\title{
International Experience Integration of Openness and Transparency Level Evaluation of Socially Oriented Non-Governmental Organizations into Russian Practice
}

\section{A.B. Novozhilov, A.V. Starshinova, and E.B. Arkhipova}

Ural Federal University named after the first President of Russia B. N. Yeltsin, Yekaterinburg, Russian Federation

\section{Abstract}

This article deals with international experience integration of openness and transparency level evaluation of activities by non-governmental organizations (NGOs) into the Russian practice. The object of this study is socially oriented non-governmental organizations - both those that receive financial support from the state and those that do not. The subject of the study is the transparency and openness of the socially oriented non-governmental organizations of the Sverdlovsk region. The article

Corresponding Author:

A.B. Novozhilov

ural.soc@mail.ru

Published: 21 January 2021

Publishing services provided by Knowledge E

(c) A.B. Novozhilov et al. This article is distributed under the terms of the Creative Commons Attribution License, which permits unrestricted use and redistribution provided that the original author and source are credited.

Selection and Peer-review under the responsibility of the XXIII International Conference Conference Committee. proposes the following hypothesis: the government provides financial support to exceptionally transparent and open socially oriented non-governmental organizations; the most popular socially oriented non-governmental organizations are considered the most transparent, and the state financial support is provided to them. To evaluate the level of openness and transparency of non- governmental organizations the authors use quantitative methodology for websites monitoring of non-governmental organizations. The indicators proposed allow for the evaluation of the current level of openness of socially oriented non-governmental organizations. In addition, the article assesses available statistics to evaluate the popularity indicator of specific socially oriented non-governmental organizations.

Keywords: non-governmental organization, openness and transparency of NGOs, financial support, social partnership, government social policy.

\section{Introduction}

Currently, non-governmental or non-profit organizations have a significant role in the economic and political development of Russia. The Government of the Russian Federation faces the tasks of activating the population creative potential, growth of volunteerism and the creation of a platform for effective communication in the process of social projects implementation. Non-profit organizations play a special role in all these processes; thus, it is interesting to analyze the current state in our country. However, along with the non-profit sector is often called not-for-profit and non-profitable; the third 
and the public; the voluntary, charitable and philanthropic; independent, public and non-governmental.

The Annual Reports of the Civic Chamber of the Russian Federation "About the state of civil society in the Russian Federation" claim a lack of transparency and openness in activities of socially oriented non-profit organizations. Scholars have discussed the need to monitor and evaluate the level of openness and transparency of socially oriented non-profit organizations. A. E. Shadrin indicates specific failures of financing of nonprofit organizations in the Russian Federation, specifically identifying the cause for their closeness and non-transparency [1]. N. D. Protasenya confirms information about the fact that the inability to evaluate the level of transparency and openness of socially oriented non-profit organizations impairs the effectiveness of such activities and their interaction with the state [2].

The practical significance of openness and transparency level evaluation of socially oriented non-profit organizations activities in the Russian Federation will provide the way to reflect specific data in the country at the moment, show the implementation rate of the legislation and find out how much financial state support is distributed rationally. In addition, the data in this field will make it possible to evaluate the effectiveness of both social policy in this field and the ongoing state support of specifically socially oriented non-profit organizations.

Based on all of the above, the research issue of this work is as follows: How does the level of openness and transparency of socially oriented non-profit organizations influence their ability to participate in the social policy of the Russian Federation?

Theoretical reviews show that the Neotokil tradition is the dominant research concept. According to this theory, civil society is a source of accumulation of social capital, which is the basis of a democratic political system and direct economic prosperity, the prosperity of the state and its liberalization [3-5].

\section{Methodology and Methods}

The theoretical basis of the study was the theory of social partnership and intersectional interaction, as well as theories explaining the institutional features of nonprofit organizations.

Web content analysis is selected as a research method. It involves an analysis of the website content of socially oriented non-profit organizations on the Internet. The purpose of this method of analysis is to determine the information transparency rate 
and consider specific parameters of transparency and openness of the activities of non-profit organizations.

\section{Results and Discussion}

The concept of "non-profit organization" appeared in connection with the work of Amitai Etzioni. He linked its appearance with an increase in the capacity to produce the good by society itself in the sphere of education, health and social protection. The third sector has become one of the alternative organizational forms of public goods production, meeting the demand for social services [6, 7]. Agents of Social Innovation are non-profit organizations; they are also new ways of doing social business in a market economy.

Lester Salamon formulated a more common and widely used definition of the "nonprofit sector" is by [8]. In his opinion, non-profit organizations must have a certain degree of institutionalization that is to be formalized. Regardless of the existence of state support, if this exists, organizations should be independent of the State. This is necessary in order to retain a balance within the public policy and implement most important concerns in social policy. As non-profits cannot make profits, their income cannot be in any way distributed among its members. In addition, the organization must remain self-governing, and volunteering needs to take for the main component of the engaged labor force.

According to Weber and Michels, there are three types of changes in institutional structures. However, in practice, it is a single process where goals change; there survival of organizations and protection of leadership shift takes place. Proponents of this model claim any organization tends to progress, and therefore its goals change, and social movement comes to an end as a collective behavior; it is transformed into a social institution. So, this is the ending of the non-profit movement.

The first stage is social unrest, in which mass actions are spontaneous, and the causes of discontent are still not understood. The second stage - popular excitement - is characterized by a high share of mass demonstrations; there is understanding of the causes of social tension and search for transformations. The third stage formalization - there is immediate movement and rules. That is quite important for advance of the discourse. The leader and participant roles are formed. The fourth stage, institutionalization, this is where a non-profit organization appears a social institution is formed, and the organization becomes official and accordingly legal.

The modern state aims at delegating some of its powers to such non-profit organizations to enable citizens to participate in policy formulation and to build trust between 
government and society. The Russian Federation identifies itself as a welfare state and moves towards an effective social policy. To achieve this goal, some of the powers in the field of social policy are delegated to socially orient non-profit organizations located in close proximity to the beneficiaries. This not only speeds up the process of receiving assistance, but also builds trust between political actors. Such a model of partnership in the relations allows not only to improve the process of obtaining assistance in socially important field, but also should be able to raise the importance, the responsibility of organizations to improve the quality of social services.

In addition, various funds and grants are established, in which individual projects of socially oriented non-profit organizations can be financially supported by the state through a competitive process, that is, to become actually recognized actors in the domestic politics of the Russian Federation. Examples of such funds are "Presidential Grants Fund". Independent public organization, whose objective is to promote common goals at the national or international level. It defines non-governmental organizations in the work of Carol Ann Tilt [11]. In addition, the need for transparency and openness of non-profit organizations as actors of social policy is highlighted $[9,10]$.

It should be noted that according to "Building strategic accountability systems for international NGOs" [12] there are three main functions of non-profit organizations. It is already above-mentioned social services, education, but, moreover, advocacy on public policy. The welfare state is the preferred form, but it does not limit the state to requiring something back for its support, nor requires the state to cooperate with all non-profit organizations, but only with friendly ones, in order to speed up the process of implementation of the planned policy.

The performance of tasks in the public interest is a key challenge for socially oriented organizations, which in turn requires a high level of transparency and openness of their activities. Foreign researchers in their works use the concept of "accountability" to define transparency and openness [13]. They highlight the need to monitor transparency and openness of non-profit organizations [14], as they are representatives of the citizens in social policy, which means that they should work for, and represent the interests of the citizens of the state, should be clear for the first sector and recipients of social services.

If a profit organization originally intended to earn profits and there is no public good, then it is easy for the recipient of social services to assess it. In the case of non-profit organizations, it is much more difficult; they are not interested in financial benefit, but the trustworthy status for them is important. Therefore, social services can be adequately provided by them. This resource must be used fairly to obtain the result, but not the commercialization of the sector in favor of concerned parties. 
Separately, the media ignored this aspect of social policy; non-profit organizations say extremely rare. It should be noted that it is still a source of information for the citizens of the country and the lack of material on nonprofit organizations causes a chain reaction of such ignorance, their rejection as a policy resource, and lack of interest in them.

Therefore, an analysis of the transparency and openness level of socially oriented nonprofit organizations can make it possible to reduce barriers and restrict their activities. It should be noted that this will identify both the relationship between the dynamics of the welfare state model and the characteristics of socially oriented non-profit organizations, and all non-profit sector of organizations.

On the basis of the above, the hypothesis was formed that (1) the government provides financial support to exceptionally transparent and open socially oriented non-profit organizations. The significance of the fulfilment of this criteria is written in the work "Social Origins of Civil Society: Explaining the Nonprofit Sector Cross-nationally" by Salamon L. M. and Anheir H. K [14]. The study revealed that in case of non-compliance with this rule there is no democratization of society but there is an increase of corruption in the interaction between government and non-profit organizations. The ineffectiveness of this activity is noted or, otherwise, a measure of transparency and openness would not be as important as it is.

The significance of popularity rating for non-profit organizations is stated in «The Value of Relationships between State Charity Regulations \& Philanthropy" by Biemesderfer D., Kosaras A. [15]. The author notes that the code of good conduct based on openness leads to the high-quality service implementation of this civil society institution and trust in them. Currently, information and communication technologies are extensively involved in the activities of society. In daily life each citizen interacts with the Internet for information, as this is the fastest and most widely available method of obtaining data. This makes the interaction more transparent and open, helping to provide an overview, identify all advantages and disadvantages of the requested object, and determine its features.

Reference should be made to regional practice; in the region through NGOs the quality of life improves, and one of the goals for this year is to achieve effective communication between NGOs, authorities and business. In the Sverdlovsk region there are more than 6.4 thousand non-profit organizations. On this indicator, Sverdlovsk region is considered one of the top ten regions. A large part of NGOs focus on social support and protection of citizens, charitable work, and activities in the field of physical culture and sports, as well as education and support of military-patriotic movements. Most of the projects of these organizations carried out in the Sverdlovsk region aim 
at improving environmental and patriotic education, harmonizing interethnic relations (102 projects), supporting motherhood and childhood, promoting a healthy lifestyle (69 projects) and activities to maintain cultural traditions and customs of the Russian peoples (25 projects)

For the 3rd quarter of 2019, 19 records of NCOs were restored. 13 non-profit organizations received subsidies from the regional budget in the amount of 14,341 thousand rubles to carry out 18 socially significant projects (events), and one non-profit organization received state support [16].

In Sverdlovsk region the websites of NCOs, the winners of the 2nd Presidential Grants competition in 2019 and projects that have not received support were examined. The analysis has shown that 12 organizations out of 59 ones as winners and 19 organizations out of 59 ones as loser do not have their websites. 19 organizations out of 47 ones as winners analyzed have no information of their heads, 27 out of them do not publish the project reports, 43 organizations have no financial documents, 30 have no statutory documents.

In 2019, the Sverdlovsk region supported the main development trend of the nonprofit sector - implementation of digital communications. A number of NGOs of the MiddleUrals have created projects based on new technologies and interactive formats.

The Ural club of new trends in education organized the accelerator "UnIT Ural", which in 2019 received support from a presidential grant. Under this project, the Sverdlovsk high school students' are interested in programming implement the most innovative ideas on the Internet environment.

Participants and finalists of the project "UnIT Ural" in 2019 founded unique services for region residents. There is a program to detect and block fake pages of celebrities automatically, a real-time virtual try-on system, and the website "Horizons of the Urals" with information of the Urals' nature and plants among them. Now the team of engineering club for kids develops a software addition to the popular computer game Mine craft that will enable students to study chemistry in the virtual world. Young programmers are also going to found a chat-bot application that will issue bar codes for children's milk supply, an automatic food ordering system for customers and restaurants/cafes staff, a fully-functional mobile app designed to help people with diabetes; an algorithm to compute the best route including such elements as traffic jams or tariff of the user's travel card. Having the experience under the project "UnIT Ural" and summer design school "TekhnoLider" (organized by the Ural club of new trends in education together with partners), one participant developed a neural network that detects tuberculosis. 
Another socially significant project - which was carried out by the Ural club of new trends in education twice in the Sverdlovsk region - is the hackathon of IT-solutions for NGOs and social projects SocialHack. In 2019, it focused on the creation of virtual and augmented reality software solutions for museums and NGOs. For instance, the winners of the hackathon coded a Virtual Tour of Constructivism Museum in Unit F App. At the moment it is posted on the Museum website.

Thus, after analyzing the website of socially oriented non-profit organizations in the Sverdlovsk region, their level of openness and transparency towards citizens can be determined. And to know whether the criterion of openness and transparency is taken into account in the selection of socially oriented organizations for incorporating into the Russian Federation social policy through direct funding from Presidential Grants. In addition, the method of web content analysis helps to assess the level of transparency and openness of socially oriented non-profit organizations at a primary and widely affordable level, and at the level of those who are the recipients of these organizations' products. This permits to do a website analysis of organizations, make an overall assessment, calculate the rate of information access and openness and transparency of socially oriented non-profit organizations to society.

A systematic approach to the study of the problem provided legal and economic assessment of this phenomenon. A more detailed overview of features that determined frameworks and specifics for civil initiatives, their dynamics of development allowed to conclude that in realities of the Russian society non-profit organizations play a fundamental role in building civil society, as well as in the systematization of relations with state structures [17]. The study has found that through their activities NGOs position themselves as a reliable partner for the non-profit sector in addressing important social challenges facing the entire society. It was also proved that cross-sector collaboration between government, nonprofit organizations and business structures is a promising vector ultimately directed at increasing the effectiveness of public administration.

The study of legal foundations of organization and activity of non-profit organizations enables us to declare that the state policy corresponds to the level of growth of the third sector. At the Federal and regional level a legal framework regulating the activities of NGOs is constantly being updated in accordance with these requirements.

However, there are a number of issues, in which the initiative should come from the federal and regional authorities: 
1. Given the importance of non-profit organizations in the system of Russian civil society and their potential, more detailed methodological work need to be undertaken, which consists of establishing them as an integrated political and socioeconomic component of civil society, developing and consolidating the conceptual framework of non-profit organizations under international law in this field.

2. With relatively well-established forms and methods of social partnership, the mechanism of cross-sector social partnership identifies a number of promising directions that are currently not developed. The development of new forms collaboration will greatly improve public administration.

3. In the scope of the interaction study between state structures and NGOs through grant activities, it is also important to systematize the competitive selection mechanisms of grant recipients. In a pre-selection phase, the community involvement will make the competition more participative.

4. Organizing and holding regular forums for the voluntary sector and the state apparatus at both federal and regional levels will facilitate continuous working collaboration.

With a view to supporting voluntary work, in February 2018 the President of the Russian Federation V.V. Putin signed a law on the status of voluntary organization, which clearly sets out the legal status of voluntary organizations, their leaders and volunteers, as well as the powers of the authorities in this field. As a result, volunteerism got more popular among business corporations that suggest a high level of corporate social responsibility development of company employees. It is no accident, therefore, that in Russia in 2014 the National Corporate Volunteer Council (NCVC) was formed at the initiative of leading domestic and international companies, the main purpose of which is to popularize socially significant volunteerism of employees and broadcast the best practices in volunteering.

By organizing corporate volunteer programs, one can identify the most popular areas for the development of NPOs in the Sverdlovsk region:

- development, support and professional orientation of children in boarding schools and orphanages;

- blood donation and assistance to those affected by emergencies;

- support to economically disadvantaged families and the elderly;

- participation in environmental volunteer initiatives, etc.; 
- participation in the development and implementation of NGO projects - professional volunteering (graphic design, project management, financial planning, etc.)

Besides, a division of an international consulting organization Accenture encourages to pay close attention to micro volunteering (MV - micro volunteering), which is carried out remotely using an office or home computer (crowd funding, software, surveys, etc.), as variability of participation in community service important for Millennials, also known as Generation Y, based on their lifestyle and personalized Internet (Internet of Me). When developing corporate volunteer programs, the following steps are recommended:

- preparation and systematization of programs in the context of the company's strategic goals; design of the potential stakeholder communication system;

- promotion of pro bono programs aimed at providing professional assistance to charitable, public and other non-profit organizations, and individuals who need this type of support, based on the level of competence development and business tasks that correlate pro bono [11];

- support of social initiatives of employees, development of corporate family volunteering, and corporate volunteer tourism (preparation of itineraries socially useful activities followed by reports on the volunteering platform).

In the implementation of volunteer programs, according to experts in the field of corporate volunteering the following recommendations must be followed up on:

1. To adapt the corporate volunteering activities to the features of the internal labor rules to reach more employees with different work schedules;

2. To take into account the priorities of the various departments that can be considered as potential partners;

3. To use a differentiated approach through the interaction with NGOs (to provide professional advice and to appoint supervisor for specific clients).

4. To develop mobile web-based platform and mobile application for client use to access the database of volunteer events, online promotions and forums.

5. To launch an elaborate PR campaign on the basis of practical experience of employees who participated in volunteer projects conducted together with NGOs. 


\section{Conclusions}

Therefore, the implementation of the above measures will enhance the potential of cross-sectoral collaboration between nonprofit organizations, the state apparatus, and effectiveness of public administration.

It was revealed by the "Methodology for websites monitoring of NGOs" that information transparency of socially oriented non-profit organizations that were integrated into the Russian social policy has a rate above $70 \%$. The level of transparency and openness of non-profit organizations that do not have access to social policy remains less than $40 \%$.

It was further suggested that the existing barriers are removed as measures to increase the level of transparency and openness of socially oriented nonprofit organizations. This is the most effective way to achieve the highest result.

From all the above it can be concluded that the level of transparency and openness of non-profit organizations does not affect their participation in social policy of the Russian Federation, but enables the nonprofit sector and the state to cooperate in regard to this policy. Information transparency ensures the state support for socially oriented nonprofit organizations and the trust of citizens. As a result, a strong policy actor is formed in social service delivery to the population.

In Sverdlovsk region the main areas for development of corporate volunteering were identified, in which the system of interaction between state structures and civil society plays special role (professional volunteering, micro volunteering, social support, and participation in the development of projects for non-profit organizations). An overview of expert advice to companies on the development and implementation of corporate volunteering programs is provided. The main development phases of corporate volunteer programs are described (preparatory promotion of pro bono, development of social initiatives, and creation of a corporate project bank). The corporate volunteering programs of major companies were analyzed that actively develop this area on the territory of the Russian Federation.

From a general point of view, it may be considered that in the Sverdlovsk region corporate volunteering is a promising practice of social and cultural partnerships for organizations that develop social responsibility and initiative of employees that generally affects the level of civic engagement of individuals in the Sverdlovsk region and the whole country. 


\section{Acknowledgments}

The article was prepared with the support of RNF on the theme of the project "Challenges of the transformation of the welfare state in Russia: institutional changes, social investment, digitalization of social services", project No. 19-18-00246 is being implemented at St. Petersburg State University.

\section{References}

[1] Shadrin, A. E. (2010). State policy of support of voluntary and charity. In: Proceedings of the IV All-Russian Conference Social partnership and the development of civil society institutions. Experience of regions and municipalities. Moscow, December 11, 2009. In V. I. Vasilenko, (Ed.). Moscow: Prospect Publishing House, pp. 59-100.

[2] Protasenya, D. N. (2017). State support for cluster development socially oriented nonprofit organizations in the Russian Federations. State and Municipal Administration. Scientific NotesSKAGS, vol. 1, pp. 1-9.

[3] Sokolowski, M. B. (2010). Social interactions in "simple" model systems. Neuron, vol. 6, issue 65, pp. 780-794.

[4] Skocpol, T. and Fiorina, M. P. (Eds.). (2004). Civic engagement in American democracy. Washington: Brookings Institution Press, p. 420.

[5] Skocpol, T. (2004). Voice and inequality: The transformation of American civic democracy. Perspectives on Politics, vol. 1, issue 2, pp. 3-20.

[6] Etzioni, A. (1973). Genetic fix: The next technological revolution. New York: Harper and Row, p. 276.

[7] Billis, D. (Ed.). (2010). Hybrid organizations and the third sector: Challenges for practice, theory and policy. London: Palgrave Macmillan, p. 256.

[8] Salamon, L. M. (2010). Putting the civil society sector on the economic map of the world. Annals of Public and Cooperative Economics, vol. 2, issue 81, pp. 167-210.

[9] Dawson, C. A. and Gettys, W. E. (1929). Introduction to Sociology. New York: Ronald Press, p. 866.

[10] Turner, R. (2017). Social psychology: Sociological perspectives. New York: Rutledge, p. 810.

[11] Tilt, C. A. (2007). NGOs: Issues of accountability, School of Commerce Research Paper Series: 05- 7, ISSN: 1441-3906. 
[12] Brown, D. L., Moore, M. H. and Honan, J. (2004). Building strategic accountability systems for international NGOs. AccountAbility Forum: Insight in Practice, issue 2, pp. 31-43.

[13] Ebrahim, A. (2003). Accountability in practice: Mechanisms for NGOs. World development, vol. 5, issue 31, pp. 813-829.

[14] Salamon, L. M. and Anheier, H. K. (1998). Social origins of civil society: Explaining the nonprofit sector cross-nationally. Voluntas: International journal of voluntary and nonprofit organizations, vol. 3, issue 9, pp. 213-248.

[15] Biemesderfer, D. and Kosaras, A. (2006). The Value of Relationships between State Charity Regulations \& Philanthropy. Retrieved January 22, 2020 from http:// coloradofunders.org/wp-content/uploads/2013/08/The-Value-of-Relationships.pdf

[16] Report on the activities and development of socially oriented non-profit organizations. 2019. Moscow: Society, p. 20.

[17] Surovneva, A. A. and Shaporov, O. A. (2018). Strategic Aspects of Development of Non-Profit Organizations in Conditions of Crisis. Journal of Ore/GIET, vol. 2, issue 44, pp.138-144. 